\title{
The thermal inertia time constants and its influencing factors in the thermal dynamic process of overhead line and cable
}

\author{
Qiying $\mathrm{Li}^{1 *}$, Yan Zhang ${ }^{2}$, Xin $\mathrm{Liu}^{2}$, Kunming $\mathrm{Hou}^{2}$, Shengyuan $\mathrm{Zhou}^{3}$ and $\mathrm{Xu} \mathrm{Jin}^{3}$ \\ ${ }^{1}$ State Grid Shandong Electric Power Company, Jinan, Shandong, 250021, China \\ ${ }^{2}$ Liaocheng Power Supply Company of State Grid Shandong Electric Power Company, Liaocheng, Shandong, 252000, China \\ ${ }^{3}$ Key Laboratory of Power System Intelligent Dispatch and Control Ministry of Education, Shandong University, Jinan, Shandong, \\ 250061, China
}

\begin{abstract}
Due to the existence of thermal capacity, the conductor temperature of overhead line and cable changes later than current steps (thermal inertia), and the thermal dynamic process of the conductor contains the huge current-carrying potential. As an important symbol of thermal dynamic process, the thermal inertia time constant is of great significance to describe the characteristics of thermal dynamic process accurately. In this paper, the thermal inertia time constants of overhead line and cable and its influencing factors are studied based on the heat balance models, which can be solved by the fourth order Runge-Kutta method. Then the four factors including the current step, ambient temperature, wind speed and global radiation intensity are used to explore their influence on the thermal inertia time constant of overhead line, and the current step and soil temperature on cable. The numerical results show the effects of influencing factors on the thermal inertia time constant and provide a theoretical basis for a more detailed evaluation of the thermal dynamic process.
\end{abstract}

\section{Introduction}

With the rapid development of the economy, the power demands of users are growing and a large number of clean energy sources are connected to power grids, which makes the load and volatility of the power grid increase significantly in the operating environment. So giving full play to the current-carrying capacity of transmission lines has attracted the attention of researchers.

Before the 1980s, the current-carrying capacity of transmission lines is defined as the static thermal rating (STR). However, the static thermal rating is determined conservatively based on the severe environment. To solve this problem, DTR technology improved the current-carrying capacity based on real operating meteorological conditions [1]. With the applications of flexible alternating current transmission system (FACTS) devices [2-3] and the DTR technology [4], the heat balance models of transmission lines were established, which made the electrothermal coupling relationship more dynamic and real. Since then IEEE [5] and CIGRE [6] respectively proposed their standards for heat balance models of overhead lines. By combining DTR technology and heat balance models with power system analysis and decision control, the dynamic thermal rating methods with forecasting [7], power system reliability evaluation [8] and control decision methods [9] were further studied in order to ensure the safe and economic operation. But the dynamic thermal rating often underestimates the current carrying because it ignores the thermal dynamic process of conductors. Based on this, [10] and [11] put forward the concept of electrothermal coordination (ETC), which expressed the transmission limitation as temperature firstly. The core of it is to introduce the temperature as the state variable into the power system analysis and optimized decision, and exploit the current-carrying capacity of transmission elements by making full use of the thermal dynamic process. Under the theoretical framework of ETC, [12] took into account the transient thermal dynamic process of overhead line in power flow and realized the safety assessment in emergencies. A temperature-dependent power flow (TDPF) was proposed in [13], which reflected the important role of thermal inertia time after the sudden change in the system state. In [14], the paper further presented a power flow calculation method considering the thermal behavior of overhead line, cable and transformer, and results showed that the thermal inertia time plays a crucial role in the security check and contingency analysis, revealing the current-carrying potential to operators.

In conclusion, the current-carrying potential in the thermal dynamic process can be valuable for power systems. However, the existing research on the thermal dynamic process is only aimed at the application level, and the thermal inertia time constants and its influencing

*Corresponding author's e-mail: dzgdgslqy@ $163 . c o m$ 
factors, as the important symbol representing the characteristics of thermal dynamic process, have not been thoroughly investigated. This paper studies the thermal inertia time constants and its influencing factors of overhead line and cable based on the heat balance models, which lays the foundation for further exerting the current-carrying potential in the thermal dynamic process of power system.

\section{Heat balance model of overhead line and cable}

As an important theoretical basis for the overhead line and cable, the heat balance models describe the relationship between temperature, current and environment, and can be used to calculate the thermal dynamic processes of transmission lines, which are summarized in this section.

\subsection{Heat balance model of overhead line}

According to the CIGRE standard [6], the heat balance model of overhead line is expressed as follows:

$$
\begin{gathered}
m C_{\mathrm{o}} \frac{\mathrm{d} \theta_{\mathrm{o}}}{\mathrm{d} t}=q_{\text {resis }}+q_{\text {solar }}-q_{\mathrm{conv}}-q_{\mathrm{rad}} \\
q_{\text {resis }}=I^{2} R_{\text {ref }}\left[1+\alpha\left(\theta_{\mathrm{o}}-\theta_{\text {ref }}\right)\right]
\end{gathered}
$$

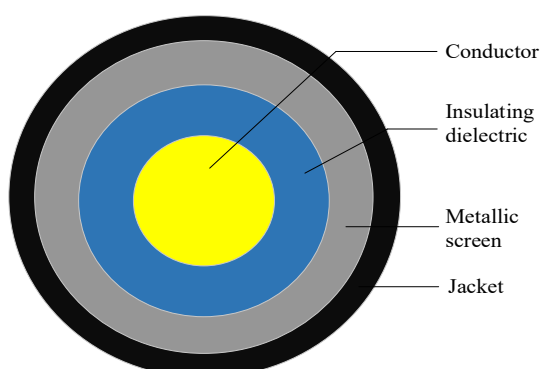

Figure 1. Structure of a single-core XLPE insulated cable.

In figure $2, W_{\mathrm{c}}, W_{\mathrm{d}}$ and $W_{\mathrm{s}}$ are conductor loss, dielectric loss and screen loss, respectively, where $W_{\mathrm{d} 1}=W_{\mathrm{d} 2}=0.5 W_{\mathrm{d}} . \theta_{\mathrm{c}}, \theta_{\mathrm{s}}, \theta_{\mathrm{j}}, \theta_{\text {soil }}$ are conductor, screen, jacket, and soil temperature, respectively. $C_{\mathrm{c}}, C_{\mathrm{d}}, C_{\mathrm{s}}, C_{\mathrm{j}}$ and $C_{\text {soil }}$ are respectively the thermal capacity of conductor, insulating dielectric, screen, jacket and soil, in which $C_{\mathrm{d} 1}=C_{\mathrm{d} 2}=0.5 C_{\mathrm{d}} . T_{1}, T_{3}$ and $T_{4}$ are the thermal resistance of insulating dielectric, jacket and soil respectively. The calculation methods of thermal resistance, thermal capacity, loss and other parameters in detail can consult in IEC standards [16-17]. Based on the thermoelectric analogy theory, the heat balance model of cable can be expressed by:

$$
\begin{gathered}
q_{\mathrm{solar}}=\beta Q_{\mathrm{se}} D \\
q_{\mathrm{conv}}=A_{\mathrm{conv}}\left(\theta_{\mathrm{o}}-\theta_{\mathrm{amb}}\right) \\
q_{\mathrm{rad}}=A_{\mathrm{rad}}\left[\left(273+\theta_{\mathrm{o}}\right)^{4}-\left(273+\theta_{\mathrm{amb}}\right)^{4}\right]
\end{gathered}
$$

where $m C_{\mathrm{o}}$ is the product of mass and specific thermal capacity; $\theta_{0}$ and $\theta_{\mathrm{amb}}$ are conductor temperature and ambient temperature respectively; $q_{\text {resis }}, q_{\text {solar }}, q_{\text {conv }}$ and $q_{\text {rad }}$ represent the joule heating, solar heating, convective cooling and radiative cooling respectively; $I$ is current; $R_{\text {ref }}$ is reference resistance; $\alpha$ is resistance-temperature coefficient; $\beta$ is solar absorptivity; $Q_{\text {se }}$ is global radiation intensity; $D$ is the diameter of conductor; $A_{\text {conv }}$ and $A_{\text {rad }}$ are convective and radiative heat transfer coefficient respectively.

\subsection{Heat balance model of cable}

The cross-linked polyethylene (XLPE) insulated cables are characterized by high mechanical strength, excellent insulation, and suitable for urban power grids and offshore wind farms. This section takes single-core XLPE insulated cable as an example, which is divided into conductor layer, insulating dielectric layer, metallic screen layer and jacket layer respectively from inside to outside, and its structure and heat balance model are shown in figure 1 and figure 2 [15].

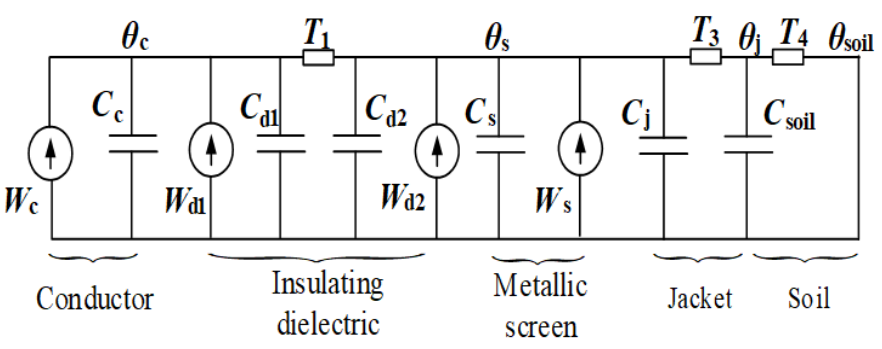

Figure 2. Heat balance model of a single-core XLPE insulated cable.

\section{Solution method}

In this paper, the fourth order Runge-Kutta method is used to solve the heat balance models of the overhead line and cable, which is a high-precision algorithm widely applied to engineering. Due to the $C_{\mathrm{o}}$ of overhead line, $C_{\mathrm{c}}, C_{\mathrm{d}}, C_{\mathrm{s}}, C_{\mathrm{j}}$ and $C_{\text {soil }}$ of cable, the temperature is inconsistent with the current steps (thermal inertia), and the thermal inertia time constant is an important symbol 
to show its characteristics. Assuming that the transmission lines have been already under the thermal steady state, the thermal inertia time constant $\tau\left(\theta_{\lambda}\right)$ is defined:

$$
\tau\left(\theta_{\lambda}\right)=t\left[\left(\theta_{\text {steady }}-\theta_{\text {initial }}\right) \times 0.632\right]-t\left(\theta_{\text {initial }}\right)
$$

where $t(\theta)$ is the time when the temperature is $\theta$ (For example, $t(\theta)$ is $t\left(\theta_{\text {initial }}\right)$ when $\left.\theta=\theta_{\text {initial }}\right) ; \theta_{\text {initial }}$ and $\theta_{\text {steady }}$ represent the initial and steady-state temperature after the conditions change, respectively.

\section{Case study}

In this section, the thermal inertia time constants are studied by taking the overhead line ACSR 400/50 and single-core XLPE insulated cable $500 \mathrm{~mm}^{2}$ as examples, whose parameters are shown in table 1.

Table 1. The parameters of the overhead line and the cable.

\begin{tabular}{|c|c|c|c|c|c|c|c|c|}
\hline \multicolumn{3}{|c|}{ the overhead line } & \multicolumn{6}{|c|}{ the cable } \\
\hline $\begin{array}{l}\text { Resistance } \\
(\Omega / \mathrm{km})\end{array}$ & $\begin{array}{c}\text { Reactance } \\
(\Omega / \mathrm{km})\end{array}$ & $m C_{\mathrm{o}}(\mathrm{J} /(\mathrm{m} \cdot \mathrm{K}))$ & $\begin{array}{c}\text { Resistance } \\
(\Omega / \mathrm{km})\end{array}$ & $\begin{array}{c}\text { Reactance } \\
(\Omega / \mathrm{km})\end{array}$ & $\begin{array}{c}\text { Conductor } \\
\text { diameter }(\mathrm{mm})\end{array}$ & $\begin{array}{c}\text { Insulation } \\
\text { diameter }(\mathrm{mm})\end{array}$ & $\begin{array}{l}\text { Metallic screen } \\
\text { diameter }(\mathrm{mm})\end{array}$ & $\begin{array}{c}\text { Outside } \\
\text { diameter }(\mathrm{mm})\end{array}$ \\
\hline 0.072 & 0.386 & 1127 & 0.056 & 0.14 & 27.5 & 61.5 & 68.7 & 76.7 \\
\hline
\end{tabular}

\subsection{Thermal inertia time constant and its influencing factors of the overhead line}

According to the heat balance model of overhead line, conductor temperature is mainly related to current, wind speed, ambient temperature and global radiation intensity. In this section, the four factors for the thermal inertia time constant will be discussed. Assuming that the overhead line has been under the thermal steady state that the initial current $I=200 \mathrm{~A}, v$ (wind speed) $=1 \mathrm{~m} / \mathrm{s}$, $\theta_{\mathrm{amb}}=20{ }^{\circ} \mathrm{C}$ and $Q_{\mathrm{se}}=300 \mathrm{~W} / \mathrm{m}^{2}$. Under the initial operating environment, the steady-state conductor temperature is $23.8^{\circ} \mathrm{C}$ by solving equations (1)-(5) based on Runge-kutta method.

Then the current steps are set as $\Delta I=100 \mathrm{~A}, \Delta I=300 \mathrm{~A}$, $\Delta I=500 \mathrm{~A}, \Delta I=700 \mathrm{~A}$ respectively, assuming that other conditions remain the same and it is under the steady state at $t=0$. The thermal dynamic processes and the thermal inertia time constants of the overhead conductor are shown in figure 3.
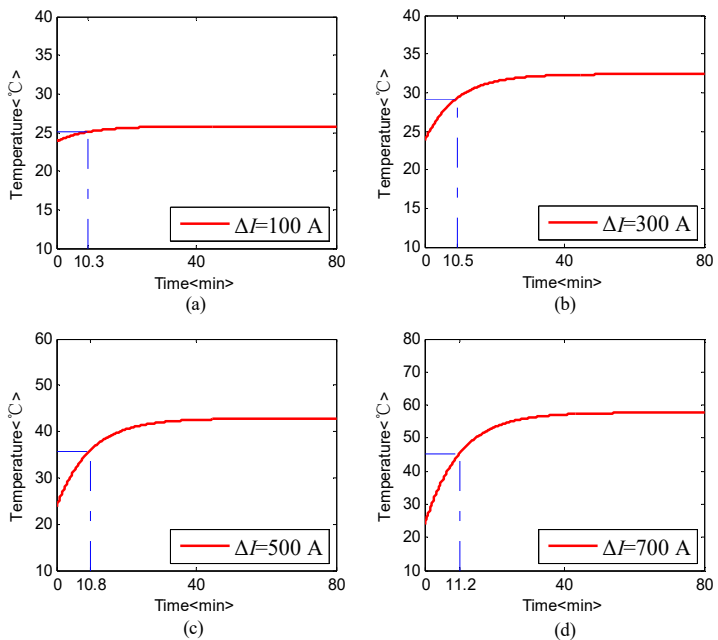

Figure 3. Thermal inertia time constants and temperature dynamics of the overhead conductor under different current steps.
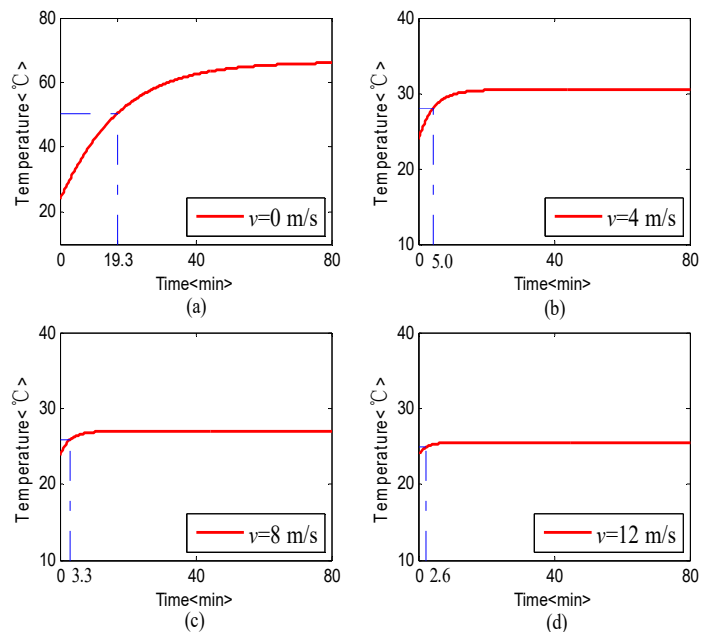

Figure 4. Thermal inertia time constants and temperature dynamics of the overhead conductor under different wind speeds.

As can be shown from figure 3 , the thermal inertia time constants of the overhead conductor range from 10.3 minutes to 11.2 minutes approximately. It can be seen that the current steps have little influence on the thermal inertia time constant, therefore when other influencing factors are studied the $\Delta I$ is uniformly set as $500 \mathrm{~A}$ to simplify the calculation in other influencing factors.

Subsequently, the wind speed is assumed to be $0 \mathrm{~m} / \mathrm{s}$, $4 \mathrm{~m} / \mathrm{s}, 8 \mathrm{~m} / \mathrm{s}$ and $12 \mathrm{~m} / \mathrm{s}$ respectively in order to study its influence on the thermal inertia time constant, and the results are shown in figure 4.

It is obvious that the thermal inertia time constants vary greatly under different wind speeds in figure 4 . The thermal inertia time constant is up to 19.3 minutes at the lowest wind speed $(0 \mathrm{~m} / \mathrm{s})$, but only 2.6 minutes at the highest wind speed $(12 \mathrm{~m} / \mathrm{s})$. This indicates that with the increase of wind speed, the dynamic thermal inertia process of overhead conductor is accelerated, which can make it reach the thermal stable state more quickly.

Similarly, the ambient temperatures are set as $-10^{\circ} \mathrm{C}$, $0^{\circ} \mathrm{C}, 10^{\circ} \mathrm{C}$ and $30^{\circ} \mathrm{C}$ and the global radiation intensity is set as $0 \mathrm{~W} / \mathrm{m}^{2}, 500 \mathrm{~W} / \mathrm{m}^{2}, 700 \mathrm{~W} / \mathrm{m}^{2}$ and $1000 \mathrm{~W} / \mathrm{m}^{2}$ 
respectively. The results of thermal inertia time constants are given in table 2 .

Table 2. Thermal inertia time constants under different ambient temperatures and global radiation intensity.

\begin{tabular}{cccc}
\hline $\begin{array}{c}\text { Ambient } \\
\text { temperature }\left({ }^{\circ} \mathrm{C}\right)\end{array}$ & $\begin{array}{c}\text { Thermal inertia time } \\
\text { constant }(\mathrm{min})\end{array}$ & $\begin{array}{c}\text { Global radiation } \\
\text { intensity }\left(\mathrm{W} / \mathrm{m}^{2}\right)\end{array}$ & $\begin{array}{c}\text { Thermal inertia time } \\
\text { constant }(\mathrm{min})\end{array}$ \\
\hline-10 & 11.1 & 0 & 10.8 \\
0 & 11.0 & 500 & 10.8 \\
10 & 10.9 & 700 & 10.7 \\
30 & 10.8 & 1000 & 10.7 \\
\hline
\end{tabular}

Table 2 shows that the ambient temperature and global radiation intensity also have little influence on the thermal inertial time constants. In summary, the thermal inertial time constant of overhead line is mainly influenced by the wind speed, and the thermal dynamic process is accelerated when the wind speed increases, which means that the thermal inertial time constant decreases.

\subsection{Thermal inertia time constant and its influencing factors of the cable}

For the cable, its initial operating conditions are assumed to be as follows: $\theta_{\text {soil }}=20^{\circ} \mathrm{C}, I=200 \mathrm{~A}$, and $U=110 \mathrm{kV}$. Under these conditions, the steady-state temperatures of conductor, screen, and jacket are $22.7^{\circ} \mathrm{C}, 21.6^{\circ} \mathrm{C}$ and $21.4^{\circ} \mathrm{C}$, respectively. Firstly, the effect of current step is studied in this section, and the four current steps are the same as the overhead line. The thermal inertia time constants and temperature dynamics of the cable conductor are shown in figure 5 .
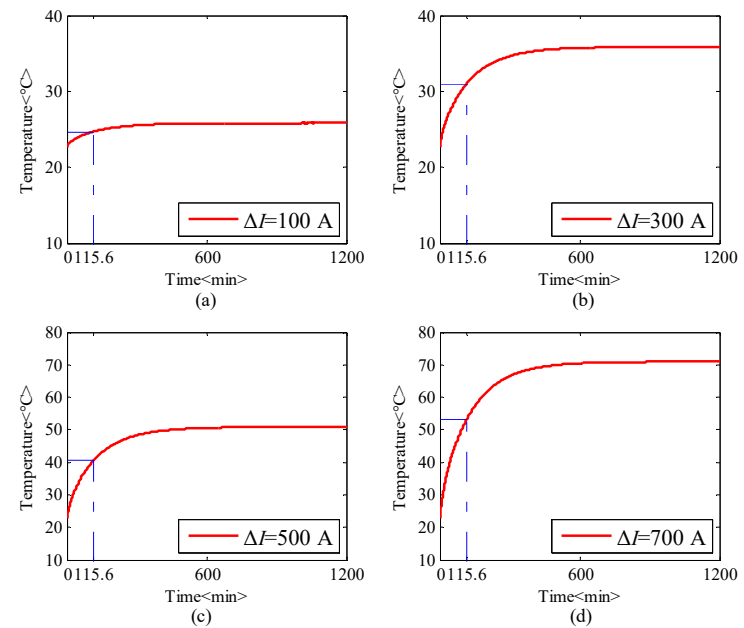

Figure 5. Thermal inertia time constants and temperature dynamics of cable conductor under different current steps.
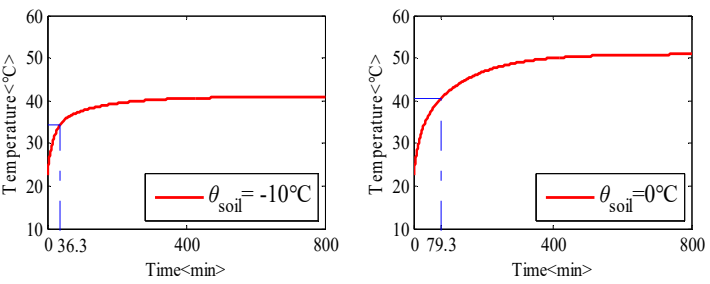

(a)
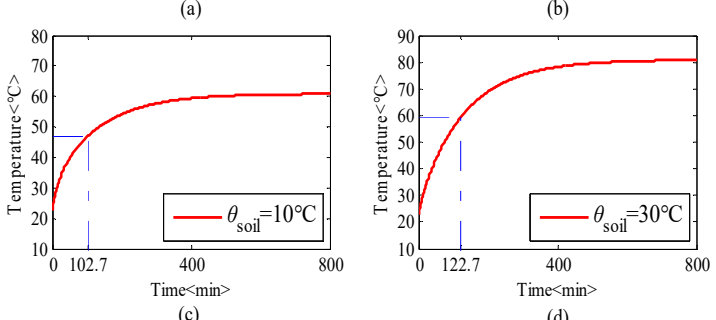

(d)

Figure 6. Thermal inertia time constants and temperature dynamics of cable conductor under different soil temperatures.

Figure 5 shows that the current steps have a slight influence on the thermal inertial time constants, which stay constant for about 115.6 minutes. So the soil temperatures are further divided into $-10^{\circ} \mathrm{C}, 0^{\circ} \mathrm{C}, 10^{\circ} \mathrm{C}$ and $30^{\circ} \mathrm{C}$ when the current step is uniformly set as $700 \mathrm{~A}$. It can be seen from figure 6 that the thermal inertia time constants of the cable conductor is greatly affected by the soil temperature, and the maximum and minimum constants are 36.3 minutes and 122.7 minutes respectively.

\section{Conclusion}

Since the temperature of the transmission lines is inconsistent with current steps, its current-carrying capacity can be embedded in the thermal dynamic process, and the accurate evaluation of the thermal inertia time constant has an important guiding role for grasping the potential. In this paper, the thermal inertia time constants and its influencing factors of overhead line and cable are studied, and the following conclusions are drawn: (1) For the overhead line, the effects of current step, global radiation intensity and ambient temperature on the thermal inertia time constants can be ignored. However, the rise of wind speed accelerates the heat exchange between the conductor and external environment significantly, which means that the thermal inertia time constants decrease sharply. (2) For the cable, the effect of current step on the thermal inertia time constants is also slight. But the soil temperature has a significant influence on the thermal inertia time constants, 
and the difference between the maximum and minimum time constants is nearly 4 times.

\section{Acknowledgments}

This work was supported in part by the Key Research and Development Plan of Shandong Province (2019GGX103044).

\section{References}

1. Davism, W. (1978) A new thermal rating approach: the real-time thermal rating system for strategic overhead conductor transmission lines, part I: General description and justification of the real-time thermal rating system. IEEE Transactions on Power Apparatus and Systems, 96: 803-809.

2. Mostafa, S.A., Seth, A.B. (2016) Transfer capability improvement through market-based operation of series FACTS devices. IEEE Transactions on Power Systems, 31: 3702-3714.

3. Abbas, R.G., Mahmud, F.F., Muhammad, O. (2015) Optimal unified power flow controller application to enhance total transfer capability. IET Generation, Transmission \& Distribution, 9: 358-368.

4. Bishnu, P.B., Jake, P.G., Timothy, M., et.al. (2018) Improvement of transmission line ampacity utilization by weather-based dynamic line rating. IEEE Transactions on Power Delivery, 33: 18531863.

5. (2013) IEEE Standard for Calculating the CurrentTemperature Relationship of Bare Overhead Conductors.

6. (2014) CIGRE Guide for thermal rating calculations of overhead lines, CIGRE WG B2.43, Technical brochures 601 .

7. Aznarte, J.L., Siebert, N. (2017) Dynamic line rating using numerical weather predictions and machine learning: a case study. IEEE Transactions on Power Delivery, 32: 335-343.

8. Xiao, R., Xiang, Y., Wang, L., et.al. (2018) Power system reliability evaluation incorporating dynamic thermal rating and network topology optimization. IEEE Transactions on Power Systems, 33: 60006011.

9. Matthias, A.B., Goran, A. (2016) Robust corrective control measures in power systems with dynamic line rating. IEEE Transactions on Power Systems, 31: 2034-2043.

10. Banakar, H., Alguacil, N., Galiana, F.D. (2005) Electrothermal coordination part I: theory and implementation schemes. IEEE Transactions on Power Systems, 20: 798-805.

11. Alguacil, N., Banakar, M.H., Galiana, F.D. (2005) Electrothermal coordination part II: case studies. IEEE Transactions on Power Systems, 20: 17381745.
12. Wang, M.X., Yang, M., Wang, J.H., et.al. (2018) Contingency analysis considering the transient thermal behavior of overhead transmission lines. IEEE Transactions on Power Systems, 33: 49824993.

13. Ngoko, B., Sugihara, H., Funaki, T. (2019) A temperature dependent power flow model considering overhead transmission line conductor thermal inertia characteristics. In: IEEE International Conference on Environment \& Electrical Engineering \& IEEE Industrial \& Commercial Power Systems Europe. Genova. pp. 125-131.

14. Zhou, S.Y., Wang, M.X., Wang, J.H., Yang, M. (2020) Time-process power flow calculation considering thermal behavior of transmission components. IEEE Transactions on Power Systems, Early Access.

15. Rasmus, O., Joachim, H., Unnur, S.G. (2013) Electrothermal coordination in cable-based transmission grids. IEEE Transactions on Power Systems, 28: 4867-4874.

16. (2006) IEC Standard-Electric Cables-Calculation of the current rating-part 1-1: Current rating equations (100\% load factor) and calculation of lossesgeneral, IEC Standard 60287-1-1.

17. (2006) IEC Standard-Electric Cables-Calculation of the current rating-part 2-1: Thermal resistancecalculation of thermal resistance, IEC Standard 60287-2-1. 